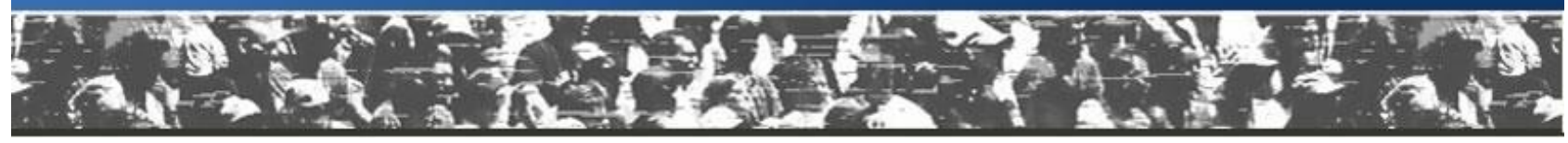

2020, Vol. 9, No. 1, pp. 44-49

\title{
Teaching Global Social Media Through Ethnography
}

\author{
Dr. Jolynna Melinda Sinanan \\ University of Sydney
}

\begin{abstract}
This short piece reflects on both the ethnographic process and the ethnographic products from the Why $W e$ Post research project, conducted between 2012 and 2017. I draw attention to the comparative nature of the project, from inception to writing up and how our comparative approach to ethnographic research has formed effective tools for teaching anthropological sensibilities to students of media and digital media studies. In the pedagogical practices that have emerged from the project, I provide examples of images posted to social media platforms and of political engagement in Trinidad as a way of drawing connections between in-depth ethnographic inquiry conducted in what may appear to be parochial or peripheral sites, and emerging trends in global, public discussion. In so doing, I illustrate the ways culturally situated digital practices can become effective and accessible ways for introducing ethnographic research into contemporary teaching contexts.
\end{abstract}

\section{Introduction}

In May 2014, nine anthropologists working on a large-scale project arrived in London after each having completed 12 months of fieldwork in nine sites: Brazil, Chile, England, India, Italy, North China, South China, Trinidad and Turkey. We were to return to our field sites after an intensive month of discussion spent honing the themes we would direct our attention towards in the last of fieldwork. Four of the anthropologists had lived for some time in London and so had homes to return to. I was one of the remaining five, who stayed for the month in a house rented on Airbnb, something that could be either an anthropologist's dream or an anthropologist's nightmare. Nearly every conversation we had started with some permutation of "In myyy field site..."; “They totally do not do that in..."; or "No, I was there, man". These conversations were how we began to develop our comparative findings on global uses of social media.

Although journal articles across the fields of digital media studies, anthropology and education are still being produced by the scholars from the UCL-based Why We Post Project (2012-2017), I've chosen here to organise the timeline for a reflection on the project around the return from 12 months of fieldwork. Indeed, May 2014 was very much the month during which we solidified our perspectives on the constellation of process, product and practice of undertaking a large-scale comparative research project and on how we would each teach about social media through our own ethnographic research. In this short piece, I draw on my fieldwork in Trinidad. Photographs and other kinds of visual content circulated over social media were one area of focus, and images posted to Facebook and Instagram became effective tools for teaching studies of media through ethnography because in these situations students didn't just 'see examples' of posts, but they were introduced to the worlds and worldviews as well as the individuals who originated such perspectives. Another area of focus was political activism. The thematic case study of a national political incident seen through the eyes of a largely rural population has increasingly resonated with the contemporary climate of ambivalence towards the role of social media in political engagement. Local-global articulations of goods and by extension, everyday meanings and practices over platforms such as Facebook, might appear parochial and peripheral, but they also contribute to a better understanding of more global concerns and processes (Miller, 1998, Wilk, 1995). 
As details of the comparative nature of the Why We Post project and of the strategy for the dissemination of findings have been given at length elsewhere (Haapio-Kirk 2017; Miller et al 2018a; Miller et al 2018b), I will offer here just some brief background. The project was led by Daniel Miller and was undertaken by a team who conducted 15 months of ethnographic fieldwork on everyday uses, consequences and contexts of social media. The more 'traditional' fieldwork was complimented by each researcher becoming familiar with participants' networks on platforms such as Facebook, WhatsApp, QQ and Instagram. In the first half of 2014, we produced short films in each field site which were then shared on YouTube and used in a FutureLearn Massive Open Online Course (MOOC): The Anthropology of Social Media. The comparative volume How The World Changed Social Media organised themes across the field sites such as education, work and commerce; it was published in 2016 and to date has been downloaded over 340,000 times in 213 countries and territoriesi. Over the following two years, the project also published a monograph dedicated to each site. An additional volume providing an in-depth comparison of visual images in two sites (England and Trinidad), Visualising Facebook was published in 2017 and aimed to address the notable absence in social media research (at the time) that several studies discussed images posted to social media but did not actually include images. At the time, Why We Post was the largest anthropology project ever funded (€2,500,000, ERC grant 2001-AdG-295486 Socnet) by the European Research Council. It was surpassed in 2018 by The Anthropology of Smartphones and Smart Ageing, a comparative project across twelve countries, also funded by the ERC, led by Miller and based at UCL.

This perhaps posturing description captures the responsibility we assumed at the time. The project had received the largest investment from a publicly funded research organisation for an anthropological project, and it included digital media for conducting and disseminating our research; so how could we maximise the opportunities presented by both? From the outset of fieldwork across nine sites, which was situated in semi-urban or rural towns with populations of between 18,000 and 25,000 people, our aim was explicitly anthropological: a commitment to holistic contextualisation of the uses of this new technological phenomenon known to the world as 'social media'. We did not know how the particular dimensions of people's lives (e.g. gender, religion, work, family) would be influenced by this object and we did not know how these same domains would influence uses, values and meanings of this object. We also refused to subscribe to the sweeping assumptions that 'social media is causing an increase in narcissistic behaviour' or 'social media is causing revolutions' that were repeatedly appearing in popular journalism until we had at least a vague sense of how 'narcissism' or 'revolution' is understood in diverse places, from Italy to Indiaii. In short, we sought out to understand, in granular detail, how people use social media in the context of everything else they do.

\section{Social Media as a Fieldwork Site}

Across 2012 to 2014, social media became a foundational tool in our ethnographic process and our ethnographic product. The project was originally conceived as one on 'Social Networking Sites and Social Science', where the most commonly used sites were Myspace, Facebook and Twitter. By the time we began fieldwork, social networking sites had been replaced by social media, where the most popular platforms included Facebook, but also Facebook Messenger as a separate mobile app and BlackBerry Messenger, which disappeared over the course of fieldwork and was almost entirely replaced by WhatsApp and Instagram. Twitter largely varied in popularity across the selection of field sites. While WhatsApp and Instagram were designed for mobile phones, there was a swift migration from using Facebook mostly on laptop or desktop web browsers to almost entirely through its app and Messenger on mobile devices. The more mobile social media became over the course of fieldwork, the more we required flexibility in our ethnographic process of hanging around in homes or meeting people while they were in their workplaces or out socialising. Conducting ethnographic research was also shaped by doing ethnography on and through social media not just about it.

Social media became a new location for fieldwork; it was a site in itself, so to speak, and although social media was the object of inquiry for this particular project, increasingly, social media was impinging on other forms of research across the field of anthropology, simply because participants in different locales were extensively using these platforms for many aspects of communication, information and entertainment in their everyday lives. Especially in anthropological studies of migration, social media was emerging as a transformative force in mobilities, identities and imaginations as part of the relationship between being home and away (Baldassar 2016; Madianou 2017; Robertson, Wilding and Gifford, 2016). On the impact of social media on how anthropologists can now go about their research, Postill and Pink argue that 'They [social media] create new sites for ethnographic fieldwork, foster new types of ethnographic practice and invite critical perspectives on the theoretical frames that dominate internet studies' (2012: 214). Indeed, by researching social media through social media, new ways of teaching through ethnography began during fieldwork. Informants made use of the affordances of camera phones to make and circulate their images and videos over platforms, many of which became valuable artefacts to inform our wider ethnographies and to draw on as ethnographic products in our teaching. 
In the context of television audiences, Pertierra argues that when consuming media texts, individuals 'are not necessarily thinking of themselves as part of an audience, and may not identify with their fellow audience members in any way' (2018: 65). When researching what people do with media to make it meaningful in their lives, an ethnographic approach inherently requires us to approach participants as individuals, with their own tastes and preferences, and to locate these in wider cultural processes. A reflective approach between individual uses of social media and locating these uses in wider cultural practices became explicitly clear in comparatively analysing images posted to platforms.

For one month in early 2014, the team concentrated on analysing images. The process included selecting 20 participants who the researcher knew quite well by that point in the fieldwork and some friends they also knew on WhatsApp, Facebook or Instagram (or, indeed, across all of these), or on QQ in the Chinese field sites. Each researcher then looked at the 50 most recent images posted by participants and tried to identify themes. While some were easily identifiable such as 'selfies', others needed more definition, such as 'humorous' or 'sentimental' memes. Analysis of images revealed what is taken as normative in one society and how it compares with that in others.

In analysing images and trying to identify patterns, we depended upon the ideas of the typical. In as much as individuals do conform and do create typicality, we also needed to investigate the mechanisms and pressures that may account for this. We were fortunate to frequently encounter perhaps the single biggest pressure encountered in social media: other people's responses to what we post. Much of the hanging around aspect of fieldwork in an ethnography of social media is looking over someone's shoulder, watching them scroll through their newsfeeds or click on the profile of a friend, peer or nemesis and commentate on what the person has posted. In Visualising Facebook, we took this approach further and included a chapter that presented perspectives of how individuals in Trinidad responded to images posted by others (2017: 185-200). The commentary was often brutally critical. For example, a man in his 30 s posted a selfie posing in a fast food restaurant and one response was simply 'I would say this is kinda sad'. And in response to a photo of a couple and a birthday cake, while some interviewees found the image 'sweet', others criticised the cake for looking like it was bought at the last minute from the local supermarket. The point of the chapter was to illustrate how cultural normativity is created and maintained.

\section{Teaching Through Ethnographies of Social Media}

In lecturing and delivering seminars in media and digital cultures, there is often a tendency to concentrate on matters of local and national significance. For students I have engaged with in Melbourne and Sydney since the project has ended, I have aimed to counter examples of teenagers preoccupied with posting photos of themselves to Facebook and Instagram - a theme that occupies public and journalistic discourse - with an explanation of how variable norms of visibility are from place to place (Sinanan 2017). By displaying and discussing images posted to the same platforms in diverse settings, social media images as embedded and emplaced within wider social and cultural practices compels media students to challenge their assumptions and introduce anthropological thinking to working with media. An ethnographic approach highlights issues of culture while remaining sceptical of both cultural and technological determinism.

In this respect, our research team has been rather fortunate that, on the whole, our main experiences of teaching anthropology have been in departments outside of the discipline (e.g. media, sociology and cultural studies) where we have incorporated our ethnographic research into courses about digital and social media. Social media is a topic that most of our students can relate to; indeed, most who are now undertaking their tertiary studies have grown up using (or at least have been exposed to) social media. It is in these instances where we can capitalise on the rich experiences and poignant stories gathered from personal engagement with our field sites that are integral to any ethnographic study.

When lecturing or giving seminars that touch upon the role that social media has played in the current climate of politics, post-truth and fake news, I usually start by giving a short explanation of where Trinidad is and why it might matter to studies of social media. At this point, some students sit up and appear interested; they guess that my point will somehow challenge or confirm their uses or assumptions about social media for political engagement. Others look polite but slightly bored; they wonder what a tiny inconsequential Caribbean island could possibly teach them about social media in Australia. In these examples, I usually give an illustration of one or two individuals, how they have reacted to a national political incident, or what they post to their own Facebook feed. I then offer a provocative but general statement that in 2016, Trinidadians (at least in my field site) were not at all surprised that Trump was elected President of the United States, because within the context 
of Trinidad, like in other anglophone decolonised Caribbean countries, such as Jamaica, politics is commonly understood as a variation of 'politricks'. Contemporary discussions around the spectacle of politics, disillusionment with current iterations with the ideological left as much as the right, disdain for elitism in political power and representation that have accelerated since social media's questionable role in political unfolding in 2016, have been long-standing concerns in the history of political engagement in Trinidad.

Visibility itself is inseparable from Trinidadian personhood and the political landscape (Birth, 2008; Burton, 1997; Hosein, 2007). Anthropological and historical scholarship on Trinidad agree on the recurrent theme of informal logics of visibility in public life. Within the intersection of the state and the social (Navaro-Yashin 2002) is the prominence of spectacle and visibility (Miller 2011; Van Koningsbruggen 1997). And Trinidadians have an everyday vernacular term for what constitutes spectacle and what it means: bacchanal, connoting mischief, chaos, and disorder (Miller 1994; Scher 2003). Because political figures actively seek to exploit the malleable nature of public visibility, it is well understood that to be engaged in politics is to engage in spectacle, which has social consequences in rural areas, such as where I conducted my fieldwork (Miller and Sinanan 2017). Political engagement from this perspective means that matters of state and public life will always have an element of havoc, disarray and irrationality. A common response to political conversation is derision or dismissal, as one high school student commented: 'Once it have anything to do with the government, we don't take it serious' which captures an expression of disillusionment on the part of individuals who feel that they cannot make a difference to wider society.

Until this decade, being a critical reader of news, current and world affairs was on par with being a good and active citizen. But since 2016, anxieties around the disintegration of democracy have entered global conversation and have rapidly increased around the world. Hannan calls the relationship between the decline in political discourse and the rise of social media 'trolling ourselves to death' (2018). He asks, 'How did we arrive in this Twilight Zone, in which the norms of public discourse appear to have broken down - this alternate universe in which brazen lies and grotesque spectacles of immaturity, incivility and obnoxiousness feel like the new normal?' (Hannan 2018: 215). Students in media studies are overly familiar with these sentiments and the point that resonates with them is that Trinidadians, for the most part, have always regarded political manoeuvring as a grotesque spectacle, amplified through mainstream, and now, social media. Perhaps for this reason, their social media literacy has always had an aspect of cynicism or at least scepticism to it; an important sensibility that is only just now being incorporated into teaching programs at higher education institutions in Australia.

\section{Conclusion}

In this short piece, I have drawn attention to the ways our ethnographic process is shaped by social media and in turn, how ethnographies of social media can become effective teaching tools. In addition to doing the things that anthropologists have always done well - maintaining a sense of holism and giving a social, historical and cultural context to the people they are studying - the ethnographic products of researching social media have enabled us to work with the expansion of digital affordances. Our ethnographies are no longer confined to the thick descriptions of penned monographs or published journal articles; they have been made accessible through websites, online courses and short films, often made in collaboration with our participants. By using the affordances provided by digital media and making comparison integral to the research process, we have hoped to come closer to the textbook definition of 'the comparative study of cultural and social life' (Eriksen 2001: 4).

\section{Acknowledgements}

This work was supported by the European Research Council (ERC grant 2001-AdG-295486 Socnet) as part of the Why We Post project, University College London. The author would like to express their gratitude to the reviewers for Teaching Anthropology and to the guest editors for this Teaching Through Ethnography: Process, Product, Practice Special Issue.

\section{References}

Baldassar, L. (2016). De-demonizing distance in mobile family lives: Co-presence, care circulation and polymedia as vibrant matter, Global Networks. 16(2): 145-163. https://onlinelibrary.wiley.com/doi/abs/10.1111/glob.12109

Birth, K. (2008). Bacchanalian sentiments: Musical experiences and political counterpoints in Trinidad, Durham: Duke University Press. 
Burton, R. (1997). Afro-Creole: Power, opposition and play in the Caribbean, Ithaca: Cornell University Press.

Eriksen, T. H. (2001). Small Places, Large Issues, London: Pluto Press.

Haapio-Kirk, L. (2017). Why We Post: digital methods for public anthropology, Teaching Anthropology. 7(1): 34-44. https://www.teachinganthropology.org/ojs/index.php/teach anth/article/view/455

Hannan, J. (2018). Trolling ourselves to death? Social media and post-truth politics, European Journal of Communication. 33(2): 214-226.

https://journals.sagepub.com/doi/abs/10.1177/0267323118760323?journalCode=ejca

Hosein, G. J. (2007). Gender, generation and negotiation among young Indian females in Trinidad (Doctoral thesis), London: University College London.

Madianou, M. (2017). "Doing family" at a distance: Transnational family practices in polymedia environments. In L. Hjorth, H. A. Horst, A. Galloway and G. Bell (eds), The Routledge Companion to Digital Ethnography. New York: Routledge, pp 102-110.

Miller, D. (2011). Tales from Facebook, Cambridge: Polity Press.

Miller, D. (1998). 'Coca-Cola: a black sweet drink from Trinidad', In D. Miller (ed) Material Cultures: Why Some Things Matter, London: UCL Press, pp. 169-188.

Miller, D. (1994). Modernity: An ethnographic approach, Oxford, UK: Berg.

Miller, D., Costa, E., Haynes, N., McDonald, T., Nicolescu, R., Sinanan, J., Spyer, J., Venkatramen, S. and Wang, X. (2018a). Contemporary Comparative Anthropology - The Why We Post Project, Ethnos: Journal of Anthropology. 84(2): 283-300 https://www.tandfonline.com/doi/abs/10.1080/00141844.2017.1397044?journalCode $=$ retn20

Miller, D., Costa, E., Haynes, N., McDonald, T., Nicolescu, R., Sinanan, J., Spyer, J., Venkatramen, S. and Wang, X. (2018b). Why We Post - a team approach to research dissemination. In V. C. Tong, A. Standen and M.

Sotirou (eds), Shaping Higher Education with Students: Ways to Connect Research and Teaching. London: UCL Press, pp. 265-269. https://www.uclpress.co.uk/products/95121

Miller, D. and Sinanan, J. (2017). Visualising Facebook: A comparative perspective, London: UCL Press. https://www.uclpress.co.uk/products/83999

Robertson, Z., Wilding, R., Gifford, S. (2016). Mediating the family imaginary: young people negotiating absence in transnational refugee families, Global Networks. 16(2): 219-236.

https://onlinelibrary.wiley.com/doi/abs/10.1111/glob.12111

Navaro-Yashin, Y. (2002). Faces of the state: Secularism and public life in Turkey, Princeton: Princeton University Press.

Pertierra, A. C. (2018). Media anthropology for the digital age, Cambridge: Polity.

Postill, J. and Pink, S. (2012). Social media ethnography: The digital researcher in a messy web, Media International Australia. 145: 23-134. https://journals.sagepub.com/doi/10.1177/1329878X1214500114

Scher, P. W. (2003). Carnival and the formation of a Caribbean transnation, Gainesville: University Press of Florida.

Sinanan, J. (2017). Social Media in Trinidad: V alues and visibility. London: UCL Press. https://www.uclpress.co.uk/products/95102

Van Koningsbruggen, P. (1997). Trinidad carnival: A quest for national identity, London: Macmillan Education. 
Wilk, R. (1995). 'Learning to be local in Belize: Global systems of common difference', In D. Miller (ed) Worlds apart: modernity through the prism of the local, London: Routledge, pp. 110- 134.

\section{Notes:}

i See https://www.uclpress.co.uk/pages/statistics for current statistics on published volumes.

2 A more recent example of social media and narcissism in media discourse: 'Attention Young People: This Narcissism Study Is All About You', The New York Times, May 15, 2919,

https://www.nytimes.com/2019/05/15/science/narcissism-teenagers.html and a reflection on the role of social media in the Arab uprisings: 'Eight years after Egypt's revolution, here's what we've learned about social media and protest, The Washington Post, January 25, 2019, https://www.washingtonpost.com/news/monkey-cage/wp/2019/01/25/eight-yearsafter-egypts-revolution-heres-what-weve-learned-about-social-media-and-protest/ 